\title{
Characteristics of the cornea in patients with pseudoexfoliation syndrome
}

\author{
Características da córnea em pacientes com síndrome de pseudoexfoliação
}

Refik Oltulu ${ }^{1}$, Gunhal Satirtav ${ }^{1}$, Emine Tinkir Kayitmazbatir ${ }^{1}$, Gulfidan Bitirgen ${ }^{1}$, Ahmet Ozkagnici ${ }^{1}$, Adnan Karaibrahimoglu ${ }^{2}$

\begin{abstract}
Purpose: To quantify the morphological alterations in corneal nerve fibers and cells in patients with pseudoexfoliation syndrome (PEX) and their relationship with the presence of hyperreflective endothelial deposits observed using in vivo confocal microscopy.

Methods: One eye each of 37 patients with PEX and 20 age-matched healthy control subjects was evaluated by in vivo corneal confocal microscopy. Patients with PEX were further classified into two groups: those with and without hyperreflective endothelial deposits. We evaluated the densities of basal epithelial cells, anterior and posterior stromal keratocytes, and endothelial cells and structure of sub-basal nerve fibers.

Results: The mean anterior and posterior stromal keratocyte and endothelial cell densities and corneal sub-basal nerve plexus variables were significantly lower in patients with PEX compared with those in healthy control subjects. The mean basal epithelial cell density did not significantly differ.

Conclusion: Eyes with PEX presented decreased corneal sub-basal nerve plexus variables and cell densities in all corneas, except for the mean basal epithelial cell density. Further, a trend of lower corneal sub-basal nerve plexus measurements in patients with hyperreflective endothelial deposits compared with those without endothelial deposits was observed.
\end{abstract}

Keywords: Cornea/physiopathology; Cornea/innervation; Exfoliation syndrome/ diagnosis; Confocal microscopy; Nerve fibers/pathology

\section{RESUMO}

Objetivo: Quantificar as alterações morfológicas nas fibras nervosas e nas células da córnea em pacientes com síndrome de pseudoexfoliação (PEX) e sua relação com a presença de depósitos endoteliais hiper-refletivos, observados por meio da microscopia confocal in vivo.

Métodos: Trinta e sete olhos de 37 pacientes portadores de PEX e 20 olhos de 20 indivíduos saudáveis, pareados por idade, foram avaliados por meio da microscopia confocal de córnea. Os pacientes com PEX foram classificados em dois grupos: pacientes sem depósitos endoteliais hiper-refletivos e pacientes com depósitos endoteliais hiper-refletivos. Células basais epiteliais, ceratócitos do estroma anterior e posterior, e densidades celulares endoteliais assim como aestrutura das fibras nervosas sub-basais foram avaliadas.

Resultados: A média de ceratócitos do estroma anterior e posterior, as densidades celulares endoteliais, bem como as variáveis de plexo nervo sub-basal foram significativamentemenores nos pacientes com PEX em comparação com indivíduos saudáveis. A densidade celular epitelial basal não diferiu significativamente.

Conclusões: Os olhos com PEX apresentaram diminuição das variáveis do plexo do nervo sub-basale das densidades celulares em toda a córnea, exceto na camada basal das células epiteliais. Além disso, foi notada uma tendência para valores mais baixos nas variáveis do plexo do nervoso sub-basal em pacientes com depósitos endoteliais hiper-refletivos em comparação àqueles sem depósitos endoteliais.

Descritores: Córnea/fisiopatologia; Córnea/inervação; Síndrome de exfoliação/diagnóstico; Microscopia confocal; Fibras nervosas/patologia

\section{INTRODUCTION}

Pseudoexfoliation syndrome (PEX) is an age-related disease characterized by the deposit of anomalous fibrillar extracellular material on intraocular structures in the anterior segment of the eye ${ }^{(1)}$. Pseudoexfoliation material (PEM) is detected by electron microscopy and indirect immunofluorescence in the stromal connective tissue of the conjunctiva, ciliary body, iris, lens capsule, and cornea. The presence of PEM on the anterior lens surface is the most consistent and important clinical diagnostic feature of PEX(2).

In vivo corneal confocal microscopy enables real-time, high resolution microscopic imaging of the cornea and has been increasingly used to evaluate the corneal changes in PEX ${ }^{(3,4)}$. Previously, the only method of delineating the structural features of this disease was pathological examination after corneal biopsy. In vivo corneal confocal microscopy allows the examination of PEX-related corneal alterations. Using in vivo confocal microscopy, Zheng et al. showed that eyes with PEX, as well as their contralateral eyes, have significantly lower cell densities in the basal epithelium, anterior and posterior stroma, and endothelium ${ }^{(3)}$. They also demonstrated the deposition of hyperreflective material on the endothelium, which they presumed to be PEM, on eyes with PEX and the contralateral eyes ${ }^{(3)}$.

To our knowledge, no study has compared the density of cells of corneal layers and the presence of hyperreflective endothelial deposits in patients with PEX. The aim of this study was to measure the density of cells in different layers of the cornea and determine whether there are morphologic changes of the sub-basal corneal nerve plexus in eyes with PEX.

\section{METHODS}

One eye each of 37 patients diagnosed with PEX without glaucoma and of 20 healthy control subjects was studied. In the patients with PEX, the eyes with more PEM as determined by biomicroscopic examination were used in the present study The study protocols were approved by the local ethics committee and follow the tenets of the Declaration of Helsinki. All patients underwent a complete

Submitted for publication: May 27, 2015

Accepted for publication: August 23,2015

Ophthalmology Department, Necmettin Erbakan University Faculty of Medicine, Konya, Turkey.

Biostatistics Unit, Medical Education and Informatics Department, Necmettin Erbakan University

Faculty of Medicine, Konya, Turkey.

Funding: No specific financial support was available for this study.

Disclosure of potential conflicts of interest: None of the authors have any potential conflict of interest to disclose.

Corresponding author: Refik Oltulu. Ophthalmology Department. Necmettin Erbakan University Meram Faculty of Medicine. Meram, Konya 42080 - Turkey - E-mail: refikoltulu@gmail.com

Approved by the following research ethics committee: Necmettin Erbakan University Meram Faculty of Medicine. Project number: $2013 / 96$. 
ophthalmic examination, and in vivo corneal confocal microscopy was performed. The diagnosis of PEX was made by visualizing PEM on the anterior lens surface and/or pupillary margin on slit-lamp biomicroscopy following pupillary dilation. On biomicroscopic examination, pigment granules were not observed on the endothelium in any patient. Based on the in vivo confocal microscopy images, one independent observer assessed the patients for hyperreflective endothelial deposits and classified the patients into two groups: patients without hyperreflective endothelial deposits (group 1, n=20) and patients with hyperreflective endothelial deposits (group 2, $n=17)$. The subjects in the control group had no history of intraocular or refractive surgery and glaucoma, no previous or active ocular disease, no corneal pathology, no prior contact lens use, and no systemic disease that may have affected the cornea. Laser scanning in vivo corneal confocal microscopy was performed on all subjects using the Rostock Corneal Module/Heidelberg Retina Tomograph III (RCM/ HRT III; Heidelberg Engineering GmBH, Dossenheim, Germany). The RCM uses an entirely digital image capture system. During the in vivo corneal confocal microscopy examination, proparacaine was instilled, and a contact lens was placed on the cornea while the patient was asked to fixate on a distant target aligned to enable examination of the central cornea. Two frames per location that contained the clearest images were selected from each of the following layers: basal epithelium, anterior stroma, posterior stroma, and endothelium. A standard central counting frame size of $200 \times 200 \mu \mathrm{m}$ was used for all epithelial and endothelial images, and a frame size of $300 \times$ $300 \mu \mathrm{m}$ was used for the stromal images. Two frames were analyzed for each corneal layer, and an average was taken. The number of cells $/ \mathrm{mm}^{2}$ was calculated by the proprietary software within the RCM/ HRT III. Three-to-five high-quality images of the sub-basal nerve plexus from the center of the cornea were assessed from each subject. For all sub-basal nerve plexus images, the full $400 \times 400-\mu \mathrm{m}$ frame was used. Automatic CCMetrics software, version 1.0 (University of Manchester, Manchester, UK) was used for the quantitative analysis of the nerve fibers. Three parameters were quantified: the corneal nerve fiber density (NFD), i.e., the total number of major nerves per square millimeter; the total length of the nerve fibers (TLNF) and branches (millimeters per square millimeter); and the nerve branch density (NBD), i.e., the number of branches emanating from the major nerve trunks per square millimeter ${ }^{(5)}$. All images were analyzed by one observer (GB), who was unaware of whether the images belonged to a patient with PEX or a control subject.

Statistical analyses were performed using SPSS software version 16.0 (SPSS Inc., Chicago, IL, USA). Descriptive analyses were presented using means and standard deviations for basal epithelial cell, anterior stromal keratocyte, posterior stromal keratocyte, and endothelial cell densities, as well as the NFD, NBD, and TLNF, and using frequencies for PEX and control groups. Statistical significance was determined by the non-parametric Kruskal-Wallis test and Mann-Whitney $U$ test. $P$-values $<0.05$ were considered statistically significant.

\section{RESULTS}

The mean age of the subjects was $68.7 \pm 4.4$ years (range, 61-76 years) in group 1, $70 \pm 5.4$ years (range, $59-85$ years) in group 2, and $67.8 \pm 2.6$ years (range, $64-74$ years) in the control group. None of the enrolled eyes had remarkable pathology of the cornea on slit-lamp biomicroscopy. There was no statistically significant difference within the three groups in terms of age $(p=0.196)$ and sex $(p=0.52)$. Table 1 shows a summary of the quantitative in vivo corneal confocal microscopy findings of the cell density measurements and nerve fiber variables in patients with PEX and healthy control subjects. Figures 1 and 2 illustrate in vivo corneal confocal microscopy images of the sub-basal corneal nerve plexus and endothelial layer, respectively, in a healthy subject, a patient without hyperreflective endothelial deposits, and a patient with hyperreflective endothelial deposits.

The mean anterior stromal keratocyte, posterior stromal keratocyte, endothelial cell densities, and the corneal sub-basal nerve plexus variables (NFD, NBD, and TLNF) were significantly lower in patients with PEX compared with those in healthy control subjects $(p<0.001)$; conversely, the mean basal epithelial cell density did not differ significantly between the two groups ( $p=0.173$ ).

When groups 1 and 2 were compared, no statistically significant differences for the corneal cell density and corneal sub-basal nerve plexus variables ( $p>0.907$ and $p>0.32$, respectively), were observed. Group 2 presented significantly lower TLNF $(p=0.024)$.

When comparing the group without hyperreflective endothelial deposits (group 1) with the control group, the mean anterior stromal keratocyte, posterior stromal keratocyte, and endothelial cell densities as well as the corneal sub-basal nerve plexus variables except for the NFD ( $p=0.310$ ) were significantly lower in group 1 subjects. There was no statistically significant difference between the two groups for the mean basal epithelial cell density $(p=0.53)$.

When comparing the group with hyperreflective endothelial deposits (group 2) with the control group, there were statistically significant differences for the corneal sub-basal nerve plexus variables and all of the corneal cell density variables except for the mean basal epithelial cell density $(p=0.447)$.

Table 1. Corneal confocal microscopic variables in patients with PEX and healthy control subjects

\begin{tabular}{|c|c|c|c|c|c|c|c|}
\hline & $\begin{array}{l}\text { Basal epithelium } \\
\left(\text { cells } / \mathbf{m m}^{2}\right)\end{array}$ & $\begin{array}{l}\text { Anterior stroma } \\
\left(\text { cells } / \mathrm{mm}^{2}\right)\end{array}$ & $\begin{array}{c}\text { Posterior } \\
\text { stroma } \\
\left(\text { cells } / \mathbf{m m}^{2}\right)\end{array}$ & $\begin{array}{c}\text { Endothelium } \\
\left(\text { cells } / \mathrm{mm}^{2}\right)\end{array}$ & $\begin{array}{l}\text { Nerve fiber density } \\
\left.\text { (fibers } / \mathrm{mm}^{2}\right)\end{array}$ & $\begin{array}{l}\text { Nerve branch density } \\
\left(\text { branches } / \mathrm{mm}^{2}\right)\end{array}$ & $\begin{array}{l}\text { Total length of } \\
\text { the nerve fibers } \\
\left(\mathrm{mm} / \mathrm{mm}^{2}\right)\end{array}$ \\
\hline Control subjects $(n=20)$ & $5913 \pm 480$ & $764 \pm 139$ & $280 \pm 49$ & $2570 \pm 369$ & $34.6 \pm 8.4$ & $73.4 \pm 32.1$ & $25.0 \pm 2.7$ \\
\hline $\operatorname{PEX}(n=37)$ & $5722 \pm 531$ & $434 \pm 131$ & $227 \pm 45$ & $2124 \pm 346$ & $28.6 \pm 9.6$ & $37.6 \pm 21.4$ & $17.3 \pm 4.2$ \\
\hline Group $1(n=20)$ & $5736 \pm 464$ & $433 \pm 131$ & $229 \pm 48$ & $2067 \pm 289$ & $30.6 \pm 10.4$ & $41.3 \pm 19.9$ & $19.0 \pm 4.4$ \\
\hline Group $2(n=17)$ & $5705 \pm 616$ & $436 \pm 134$ & $225 \pm 42$ & $2190 \pm 403$ & $26.2 \pm 8.2$ & $33.3 \pm 22.9$ & $15.3 \pm 3.0$ \\
\hline \multicolumn{8}{|l|}{$P$ values } \\
\hline Control subjects vs. PEX & 0.173 & $<0.001$ & $<0.001$ & $<0.001$ & $<0.001$ & $<0.001$ & $<0.001$ \\
\hline $\begin{array}{l}\text { Control subjects vs. } \\
\text { group } 1\end{array}$ & 0.530 & $<0.001$ & 0.010 & $<0.001$ & 0.310 & 0.004 & 0.001 \\
\hline $\begin{array}{l}\text { Control subjects vs. } \\
\text { group } 2\end{array}$ & 0.447 & $<0.001$ & 0.004 & 0.027 & 0.004 & $<0.001$ & $<0.001$ \\
\hline Group 1 vs. group 2 & 0.982 & 1 & 1 & 0.907 & 0.278 & 0.759 & 0.024 \\
\hline
\end{tabular}



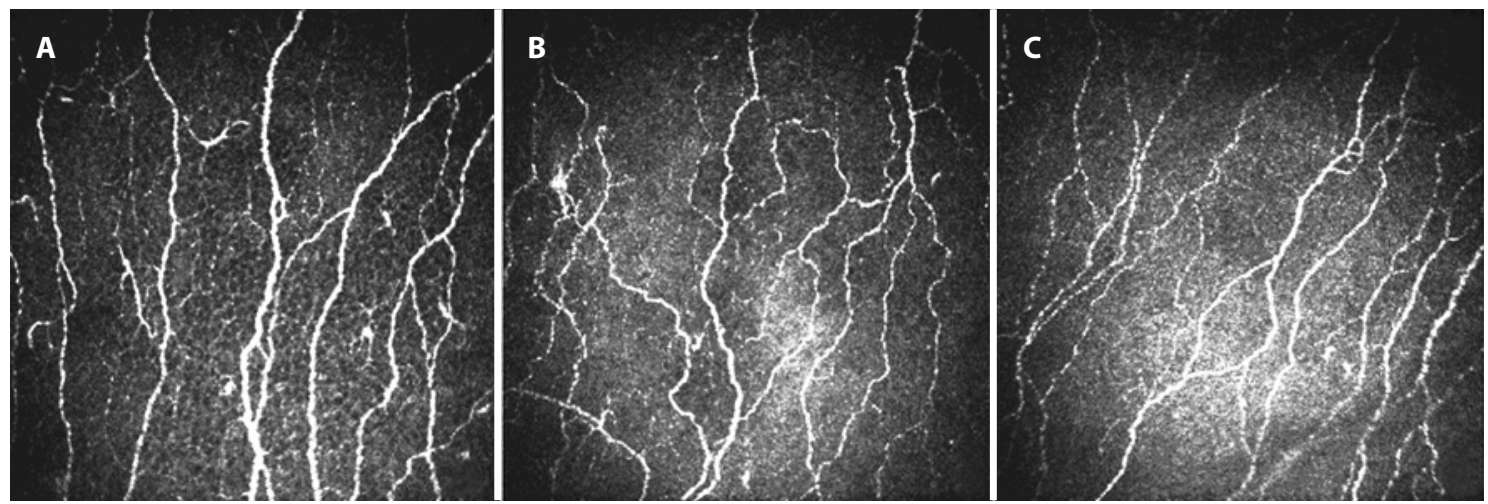

Figure 1. In vivo confocal microscopic images of the sub-basal nerve plexus. (A) Representative image from a healthy control subject with normal corneal nerve fibers. (B) Representative image from a patient without hyperreflective endothelial deposits showing lower nerve branch density (branches $/ \mathrm{mm}^{2}$ ) and the total length of the nerve fibers $\left(\mathrm{mm} / \mathrm{mm}^{2}\right.$ ) compared with the control. (C) Representative image from a patient with hyperreflective endothelial deposits showing lower nerve fiber density (fibers $/ \mathrm{mm}^{2}$ ), nerve branch density (branches $/ \mathrm{mm}^{2}$ ), and the total length of the nerve fibers $\left(\mathrm{mm} / \mathrm{mm}^{2}\right)$ compared with the control.
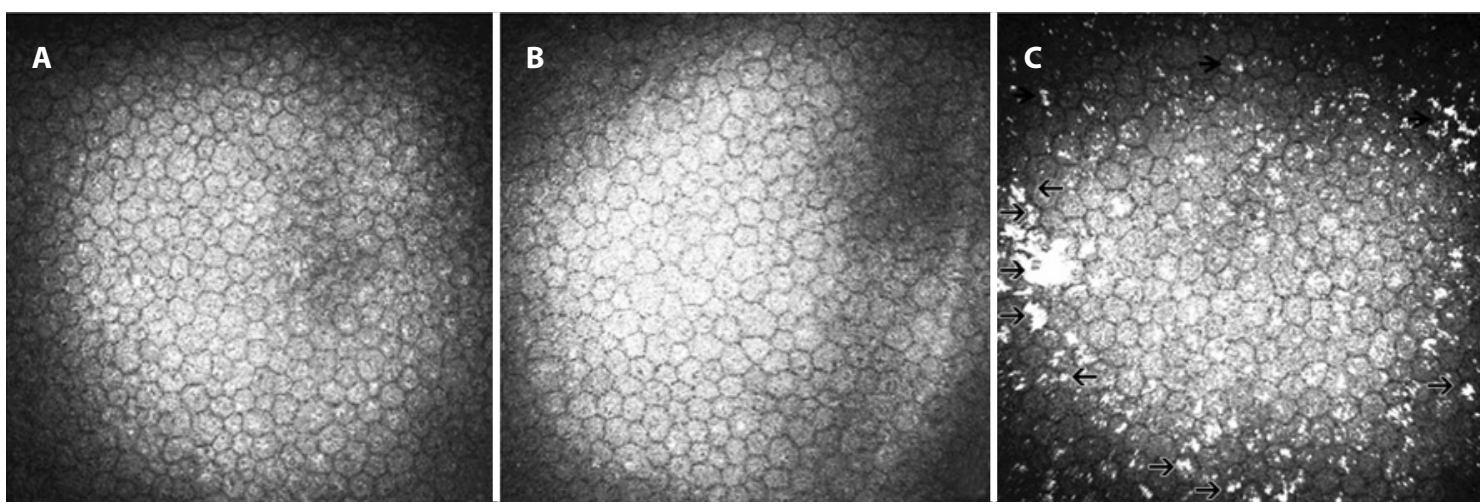

Figure 2. In vivo confocal microscopic images of the endothelial layer. A) Representative image from a healthy control subject with a normal endothelial layer. B) Representative image from a patient without hyperreflective endothelial deposits. C) Representative image from a patient with hyperreflective endothelial deposits (arrowheads).

\section{DISCUSSION}

In vivo confocal microscopy offers direct, non-invasive visual access to the cornea at the cellular level and also permits evaluation of the sub-basal nerve plexus ${ }^{(6)}$. A few studies in the literature have used in vivo corneal confocal microscopy to study the corneas of patients with PEX. Martone et al. detected hyperreflective deposits and dendritic cells infiltrating the basal epithelial cell layer in one case using in vivo corneal confocal microscopy ${ }^{(7)}$. They also found fibrillar subepithelial structures, and the endothelial layer showed cellular anomalies. In a prospective observational case series, Sbeity et al. used noncontact in vivo corneal confocal microscopy to detect PEM on the lens surfaces and corneal endothelium of PEX eyes and their fellow eyes ${ }^{(8)}$. Moreover, Zheng et al. demonstrated a decrease in corneal sensitivity as well as all of the corneal cell density and corneal sub-basal nerve plexus variables in patients with PEX(3)

In our study, we studied the cell density in different layers of the cornea and aimed to determine whether there are morphologic differences in the sub-basal corneal nerve plexus between eyes with and without PEX. We found no significant difference in the mean basal epithelial cell density between groups 1 and 2 and between patients with PEX and healthy control subjects. This finding contradicts those of previous studies, which showed significant differences in the mean basal epithelial cell density between patients with PEX and healthy control subjects ${ }^{(3,4)}$.
We further observed significantly lower anterior and posterior stromal keratocyte densities in patients with PEX compared with healthy control subjects. However, these variables did not significantly differ between groups 1 and 2. Zheng et al. observed PEM deposits in the anterior stroma of PEX eyes and suggested that the PEM may somehow cause PEX, perhaps by inducing apoptosis of the keratocytes as well as other pathogenic factors, such as altered levels of cytokines or chemokines in the cornea ${ }^{(3)}$.

Oxidative stress is generally induced through the formation of multiple reactive oxygen species, including superoxide, hydrogen peroxide, and hydroxyl radicals, which can initiate and propagate free radicals. The net oxidative burden between the prooxidant and antioxidant systems represents the oxidative stress that damages cellular and tissue macromolecules, such as lipids, proteins, and nucleic acids, and results in cellular and tissue dysfunction and cellular death ${ }^{(9)}$. The numbers of keratocytes and other cells of the cornea may decline with age in response to cumulative oxidative insults or declining antioxidant protection ${ }^{(10)}$. Demirdögen et al. reported that the total antioxidant status (TAS) levels were significantly lower in patients with PEX and pseudoexfoliation glaucoma (PG) compared with that in controls, and that lack of antioxidants may play an important role in the development of PEX/PG ${ }^{(11)}$. This reduced level of antioxidants may be a contributing factor in the lower keratocyte density in patients with PEX compared with that in control subjects found in 
our study, although stromal deposits were not found in any of the patients. Additionally, the lack of any difference between groups 1 and 2 concerning the keratocyte density, together with the previously reported decreased TAS levels in patients with PEX, supports the altered cytokine and chemokine level hypothesis suggested by Zheng et al. ${ }^{(3)}$. Furthermore, groups 1 and 2 did not differ with regard to the cell numbers in the corneal layers, and therefore, the presence or absence of PEM on the endothelium does not affect the number of cells; instead, a secondary mechanism is thought to affect the cell numbers.

Various studies have described the changes in the histopathological endothelial characteristics ${ }^{(3,7,12)}$, although few used in vivo corneal confocal microscopy to analyze the possible differences between patients with and without PEX. Zheng et al. observed not only lower endothelial cell density but also increased degrees of pleomorphism and polymegathism and a higher coefficient of variation in the cell sizes in the patients with PEX compared with those in the healthy control subjects ${ }^{(3)}$. We found that the mean endothelial cell density was lower in patients with PEX compared with that in healthy control subjects. Although we observed qualitative variation in the size and shape of the endothelial cells in eyes with PEX, quantitative analysis of pleomorphism and polymegathism was not performed in the current study, which limits detailed analysis. Deposition of PEM has been described as irregular clumps deposited on the corneal endothelium and has been associated with a decrease in the endothelial cell count ${ }^{(13)}$. However, there was no statistically significant difference in the mean endothelial cell density when comparing group 1 with group 2. This suggests that factors other than the presence of PEM may be associated with the reduction of the endothelial cell density.

Abnormalities of the sub-basal nerve plexus were another important finding of the present study. We found that NFD, NBD, and TLNF were significantly lower in patients with PEX compared with those in healthy controls; additionally, we further showed that TLNF was significantly lower in group 2 compared with that in group 1. Additionally, neither NFD nor NBD differed significantly among the study subgroups, although both of them tended to be lower in group 2 compared with those in group 1. The reason for this may be that the two groups were at different stages of the PEX process; the eyes in group 1 may have been at an early stage of PEX.

There were some limitations in this study. First, the quantitative analysis of the in vivo corneal confocal microscopy images was performed by an observer who was unmasked regarding whether the images belonged to a patient with PEX or a control subject. Secondly, the study groups had small sample sizes. However, the sample sizes of our report are comparable with those of similar studies in the literature. Another factor that could be considered as a limitation in this study is the possible effect of the presence of hyperreflective endothelial spots on the accuracy of measurements of the sub-basal nerve plexus variables. Further studies are needed to address whether the etiology of the differences between the measurements of the groups was due to an actual effect of the presence of hyperreflective spots on the nerve variables or an artifact effect of these deposits that limited the accuracy of the measurements.

In conclusion, in vivo corneal confocal microscopy permits in vivo imaging of microstructural changes in the corneas of patients with PEX. Our study demonstrated that eyes with PEX have lower cell densities in all layers of the cornea except for the basal epithelium, as well as the corneal sub-basal nerve plexus variables, compared with those in control subjects. Further, we found trends toward lower corneal sub-basal nerve plexus measurements in patients with hyperreflective endothelial deposits compared with those in subjects without hyperreflective endothelial deposits. Further studies are needed to elucidate the relationships between hyperreflective endothelial deposits and in vivo corneal confocal microscopy findings.

\section{REFERENCES}

1. Schlötzer-Schrehardt U, Naumann GO. Ocular and systemic pseudoexfoliation syndrome. Am J Ophthalmol. 2006;141(5):921-37.

2. Schlötzer-Schrehardt U, von der Mark K, Sakai LY, Naumann GO. Increased extracellular deposition of fibrillin-containing fibrils in pseudoexfoliation syndrome. Invest Ophthalmol Vis Sci. 1997;38(5):970-84.

3. Zheng X, Shiraishi A, Okuma S, Mizoue S, Goto T, Kawasaki S, et al. In vivo confocal microscopic evidence of keratopathy in patients with pseudoexfoliation syndrome. Invest Ophthalmol Vis Sci. 2011;52(3):1755-61.

4. Zheng X. New findings for an old disease: morphological studies on pseudoexfoliation syndrome-related keratopathy and binocular asymmetry. Cornea. 2013;32(Suppl 1): S84-90.

5. Dabbah MA, Graham J, Petropoulos IN, Tavakoli M, Malik RA. Automatic analysis of diabetic peripheral neuropathy using multi-scale quantitative morphology of nerve fibres in corneal confocal microscopy imaging. Med Image Anal. 2011;15(5):738-47.

6. Guthoff RF, Zhivov A, Stachs O. In vivo confocal microscopy, an inner vision of the cornea-a major review. Clin Exp Ophthalmol. 2009;37(1):100-17.

7. Martone G, Casprini F, Traaversi C, Lepri F, Pichierri P, Caporossi A. Pseudoexfoliation syndrome: in vivo confocal microscopy analysis. Clin Exp Ophthalmol. 2007;35(6):582-5.

8. Sbeity Z, Palmiero PM, Tello C, Liebmann JM, Ritch R. Non-contact in vivo confocal scanning laser microscopy in exfoliation syndrome, exfoliation syndrome suspect and normal eyes. Acta Ophthalmol. 2011;89(3):241-7.

9. Tanito M, Kaidzu S, Takai Y, Ohira A. Status of systemic oxidative stresses in patients with primary open-angle glaucoma and pseudoexfoliation syndrome. PLoS One. 2012; 7(11):e49680.

10. Patel S, McLaren J, Hodge D, Bourne W. Normal human keratocyte density and corneal thickness measurement by using confocal microscopy in vivo. Invest Ophthalmol Vis Sci. 2001;42(2):333-9.

11. Demirdögen BC, Ceylan OM, Işikoğlu S, Mumcuoğlu T, Erel O. Evaluation of oxidative stress and paraoxonase phenotypes in pseudoexfoliation syndrome and pseudoexfoliation glaucoma. Clin Lab. 2014;60(1):79-86.

12. Quiroga L, Lansingh VC, Samudio M, Peña FY, Carter MJ. Characteristics of the corneal endothelium and pseudoexfoliation syndrome in patients with senile cataract. Clin Experiment Ophthalmol. 2010;38(5):449-55.

13. Naumann GO, Schlötzer-Schrehardt U. Keratopathy in pseudoexfoliation syndrome as a cause of corneal endothelial decompensation. A clinicopathologic study. Ophthalmology. 2000;107(6):1111-24. 